DOI 10.37882/2223-2982.2021.05-3.08

\title{
РАЗРАБОТКА ТЕСТОВЫХ ЗАДАНИЙ ПО ДИСЦИПЛИНЕ «ИНОСТРАННЫЙ ЯЗЫК В СФЕРЕ ПРОФЕССИОНАЛЬНОЙ КОММУНИКАЦИИ» ДЛЯ ПРОВЕДЕНИЯ КОНТРОЛЯ В ДИСТАНЦИОННОЙ ФОРМЕ
}

\section{DEVELOPMENT OF TEST TASKS IN THE DISCIPLINE "FOREIGN LANGUAGE IN THE FIELD OF PROFESSIONAL COMMUNICATION" FOR REMOTE CONTROL}

\section{N. Klimova \\ E. Kovalenko \\ O. Goroshko \\ E. Shevchenko}

Summary: The article discusses the basic principles of developing test tasks. An example of the development of test tasks in the discipline "Foreign language in the field of professional communication" for students of the training direction 19.03.04 "Product technology and catering" for remote control is described.

Keywords: foreign language, professional communication, test tasks, distance learning.

\section{Климова Наталья Юрьевна}

К.и.н., доцент, Институт сервиса, туризма и дизайна (филиал) Северо-Кавказского федерального университета в г. Пятигорске nazar11081@mail.ru

Коваленко Екатерина Святославовна Институт сервиса, туризма и дизайна (филиал) СевероКавказского федерального университета в г. Пятигорске katusha.2013-kovalenko@yandex.ru

Горошко Ольга Николаевна

К.и.н., доцент, Институт сервиса, туризма и дизайна (филиал) Северо-Кавказского федерального университета в г. Пятигорске goroshko_olenka@mail.ru

Шевченко Елена Михайловна

К.и.н., дочент, Институт сервиса, туризма и дизайна (филиал) Северо-Кавказского федерального университета в г. Пятигорске

lena.shevchenko.1976@list.ru

Аннотация: В статье рассматриваются основные принципы разработки тестовых заданий. Описан пример разработки тестовых заданий по дисциплине «Иностранный язык в сфере профессиональной коммуникации» для студентов направления подготовки 19.03.04 «Технология продукции и организация общественного питания» для проведения контроля в дистанционной форме.

Ключевые слова: иностранный язык, профессиональная коммуникация, тестовые задания, дистанционное обучение.

обучения, не снизив уровень и качество подготовки. Произошедшие изменения коснулись организации учебного процесса, методов обучения и подхода к преподаванию.

Любое обучение подразумевает контроль. Все студенты проходят промежуточный контроль знаний в процессе обучения и итоговый квалификационный. Традиционно в образовании сложилось три формы контроля: устная, письменная, тестовая. Наиболее часто применяемой формой контроля в дистанционном обучении является тестирование.

Тестирование - метод выявления и оценки уровня учебных достижений обучающихся, осуществляемый посредством тестовых заданий, реализуемый в форме алгоритмически упорядоченного взаимодействия сту- 
дента с системой тестовых заданий.

Объективность результатов тестирования зависит от качества тестовых материалов, поэтому при разработке необходимо учитывать комплекс требований, диктуемых положениями теории и практики тестирования:

- полный охват тестом требований ФГОС и учебной программы дисциплины;

- правильность пропорций, выбранных при отображении разделов предмета, и их соответствие спецификации;

- проверка каждым тестовым заданием усвоения конкретного элемента учебного материала;

- формулировка тестовых заданий в виде кратких суждений в повествовательной форме (желательно не более 15 слов);

- избегание преднамеренных подсказок, сленга в тексте, а также сложноподчинённых предложений и повелительного наклонения («выберите», «вычислите», «укажите» и т.п.);

- ориентация тестового задания на получение однозначного ответа;

- использование тестовых заданий различных тестовых форм и категорий трудности.

Категория трудности тестовых заданий определяется разработчиком и указывает субъективную величину сложности решения данного теста. Назначение нормы трудности осуществляется, исходя из принадлежности задания основному и дополнительному материалам (уровень значимости), а также «глубины» спецификации теста, раскрывающей уровень иерархии спецификации теста (понятие, подтема, раздел и т.п.).

Система онлайн-тестирования - это универсальный инструмент для определения качества подготовки студентов на всех уровнях образовательного процесса. В современных условиях овладение методикой тестирования и создание баз тестовых заданий по учебным дисциплинам требует больших трудозатрат педагогов. Создание тестов на высоком методологическом уровне требует от преподавателя разработки четкой понятийно-терминологической структуры курса, т.е. таблицы проверяемых в тестах понятий и тезисов, структурированных по темам и разделам программы учебной дисциплины [2]. Сегодня тестовые экзаменационные материалы - своеобразный тренд в образовании, поскольку позволяют быстро получить точный и объективный результат. Тесты хороши и тем, что это автоматизированная система проверки знаний, не требующая непосредственного участия преподавателя. Тестовые задания могут быть разными, обычно время ответа ограничено, чтобы студент не мог «подсмотреть» информацию в учебниках или интернете. Проводится такой контроль обычно онлайн на портале учебного заведения.
Преподаватели кафедры лингвистики и межкультурной коммуникации филиала СКФУ в г. Пятигорске разработали банк тестовых заданий по ряду дисциплин кафедры: «Иностранный язык», «Второй иностранный язык» (немецкий, французский), «Деловой иностранный язык», «Иностранный язык в сфере профессиональной коммуникации» и др. Актуальность и значимость учебной дисциплины «Иностранный язык в сфере профессиональной коммуникации» заключается в том, что её освоение способствует развитию коммуникативных навыков и языковой компетенции, необходимых для успешной профессиональной и научной деятельности выпускников. Таким образом, разработка тестовых заданий по дисциплине также имеет большую значимость. Тестовые задания по дисциплине «Иностранный язык в сфере профессиональной коммуникации» имеют свою специфику: они направлены на проверку грамматики и лексики профессиональной направленности.

Тестовые задания используются для контроля и оценки образовательных достижений студентов, освоивших программу учебной дисциплины, составляются в точном соответствии с программой (учебником) или изученным материалом [5]. В целях оптимизации иноязычной профессионально-коммуникативной подготовки бакалавров и магистрантов неязыкового вуза преподавателями кафедры лингвистики и межкультурной коммуникации филиала СКФУ в г. Пятигорске разработаны методические указания по выполнению практических работ по дисциплине «Иностранный язык в сфере профессиональной коммуникации» по различным направлениям подготовки (равно как и по всем другим дисциплинам кафедры), которые являются основным учебным материалом и успешно используются на практических занятиях. Как известно, методические указания по выполнению практических работ являются одной из составляющих УМКД и базовым средством обучения. Например, методические указания по выполнению практических работ по дисциплине «Иностранный язык в сфере профессиональной коммуникации» для студентов направления подготовки 19.03.04 «Технология продукции и организация общественного питания» (в нашем случае это английский язык). Данные методические указания состоят из нескольких тематических разделов, каждый из которых включает определенное количество практических занятий, соответствующее рабочей программе дисциплины: Раздел 1. My profession / Моя профессия. Раздел 2. Main types of public catering. Establishments. Equipment / Основные виды общественного питания. Учреждения. Оборудование. Раздел 3. Food and beverages /Еда и напитки. Раздел 4. Crockery. Cutlery. Glassware. Napkins / Посуда. Столовые приборы. Изделия из стекла. Салфетки [1]. С опорой на данный учебный материал разрабатывались тестовые задания по дисциплине «Иностранный язык в сфере профессиональной коммуникации» для студентов направления 19.03.04 «Технология продукции 
и организация общественного питания», которые представляют собой тестовые задания разных типов и включают в себя задания на проверку грамматики и лексики профессиональной и деловой направленности.

Принципы разработки заданий в тестовой форме связаны с их формами. Разные авторы по-разному классифицируют формы тестовых заданий [4]. Положение усложняется тем, что каждая автоматизированная система для проведения тестирования называет одни и те же формы по-разному. Обобщим все многообразие форм тестовых заданий следующей классификацией. Тестовые задания делят на две большие категории: тестовые задания закрытого типа и тестовые задания открытого типа.

В тестовых заданиях закрытого типа содержатся вопросы и даются варианты ответов на них. При этом могут быть задания с одним и с несколькими вариантами ответов. В группу заданий закрытого типа объединяют следующие задания: верно/неверно - содержит утверждение, с которым обучающийся должен либо согласиться, либо нет; задания множественного выбора - задания с выбором одного или нескольких правильных ответов; задания на установление соответствия.

Задания верно/неверно, множественного выбора и соответствия обладают следующими общими чертами:

- верный ответ присутствует в явном виде, его необходимо просто выбрать тем или другим способом;

- ответы на вопросы можно угадать (вероятность угадывания вырастает с уменьшением количества альтернатив);

- ответы можно вспомнить;

- ответы можно подобрать логически, откинув явно неправильные альтернативы.

Приведём несколько примеров тестовых заданий по дисциплине «Иностранный язык в сфере профессиональной коммуникации» для студентов направления 19.03.04 «Технология продукции и организация общественного питания». Задания множественного выбора - самая распространённая форма тестовых заданий. Задание содержит утверждение (вопрос) и альтернативные ответы. Для заданий с выбором одного правильного ответа рекомендуется не менее 4 (если меньше, то вероятность угадывания правильного ответа увеличивается) и не более 6 (трудно придумать правдоподобные альтернативы). Для заданий с выбором нескольких правильных ответов рекомендуется не менее 6 альтернатив. При этом вопрос должен быть четко и грамотно сформулирован, а все варианты ответов должны выглядеть правдоподобно. При этом студент, не знающий учебный материал, не сможет просто отбросить нелогичный или нелепый ответ (плюсами отмечены правильные ответы):
Style or method of cooking

+ cuisine

- waiter

- establishment

- restaurant

A person who takes orders and caters to the food and drink needs of customers in a restaurant

- manager

- customer

- co-worker

+ waiter

A summary of your professional and academic life

- a professional waiter

+ Curriculum Vitae

- a letter of invitation

- applying for a job

Name, address, email and telephone number (and sometimes nationality, age/date of birth and marital status)

+ personal details

- personal interests

- work experience

- education

It is served in a British pub

- fusion cuisine

- vegetarian food

- pizzas and pasta dishes

+ traditional English fish and chips

Mozzarella and Mascarpone

- hard cheeses

+ soft cheeses

- blue cheeses

- soft creamy blue cheeses

This type of wines - luxurious wines that are filled with bubbles of gas by special production methods.

- red wine

- rosé wine

- fortified wine

+ sparkling wine

Name the group of following products: tuna, salmon, carp, herring.

- vegetables

- meat

- poultry

+ fish

- fruit

- dairy products

Задания на установление соответствия представляют собой набор элементов в двух столбцах: студенту нуж- 
но установить соответствие между элементами левого и правого столбцов. В подобных тестовых заданиях количество вариантов ответов может быть как одинаковым, так и избыточным. В качестве примеров на соотнесение можно привести следующие:

Соответствие между английскими и русскими эквивалентами

$\begin{array}{ll}\text { cafe } & \text { кафе } \\ \text { snack-bar } & \text { закусочная } \\ \text { confectionery shop } & \text { кондитерская } \\ & \text { овощной магазин }\end{array}$

Соответствие между английскими и русскими эквивалентами

$\begin{array}{ll}\text { waiter } & \text { официант } \\ \text { customer } & \text { клиент } \\ \text { employee } & \text { сотрудник } \\ & \text { продавец } \\ & \text { повар }\end{array}$

Соответствие между английскими и русскими эквивалентами

to deliver food and drinks доставлять еду и напитки

to serve customers обслуживать клиентов

to take orders принимать заказы принимать оплату носить униформу

Тестовые задания открытого типа. Эти задания имеют, как правило, более высокую сложность. Они могут требовать краткого ответа, либо развернутого суждения по какой-либо тематике. Эссе - еще один вид открытых тестовых заданий, требующий развернутого ответа, суждения, краткий ответ учащегося по сути вопроса. Строго говоря, эссе не является формой тестового задания, т.к. оно не соответствует необходимым критериям краткости, технологичности и т.п. Специфической чертой тестов по иностранным языкам является задание на прослушивание аудиотекста (аудирование). Мы не будем подробно останавливаться на эссе и аудировании, т.к. не использовали подобные задания по причине сложности оценивания таких тестовых заданий при дистанционном обучении.

Как мы уже отметили, задания открытой формы вызывают более высокую сложность, т.к. не предполагают вариантов ответов. Поэтому при составлении подобных тестовых заданий необходимо помнить о том, что вариант ответа должен быть единственно возможным. Такое задание, например, составлено не верно: The of this restaurant are celebrities and wealthy tourists. Вариантами ответа могут быть: customers, visitors, guests и т.п. Предлагаем следующие варианты тестовых заданий открытой формы:
Camembert is the famous French soft (cheese)

When you apply for a , employers ask for two important documents: a CV or Resume and a covering letter. ( job)

are food service professionals who take orders and cater to the food and drink needs of customers in a restaurant. (Waiters, waiters) В подобных заданиях надо учитывать, что студент может написать недостающее слово со строчной буквы и тогда автоматически оно не будет засчитано, поэтому при формировании правильных ответов обязательно нужно указывать все возможные варианты их написания.

Traditional British serves traditional English fish and chips and a good range of beers and ales. (pub)

Red is made from black grapes. (wine)

- drinks that are made by mixing, shaking or stirring liquor and/ or wine with other ingredients. (Cocktails, cocktails)

A special Russian dish is "pyelmeni" - small cases of pasta containing chopped (meat)

A represents the range of food and beverage items offered in a restaurant. (menu)

The New Zealand wine more expensive than the Portuguese wine in this restaurant. (is)

The French wine we had was better the Chilean. (than)

A traditional Russian must always start with a soup. (dinner)

A ___ is used for wiping the mouth after a meal is finished. (napkin)

A is covered with a tablecloth before setting. (table)

we came, the restaurant had already closed. (When, when)

I worked in this restaurant 1955 to 1960 . (from)

Helen asked me if I eaten a Yorkshire pudding. (had)

Nowadays a typical English consists of a bowl of cereals, a slice of toast, orange juice and a cup of coffee. (breakfast) 
When the meal is over, the waiter brings you a made out by the cashier. (bill)

You may also have an aperitif - a drink the meal to stimulate the appetite, e.g. a gin and tonic. (before)

When the meal is over you ask the bill/ the check (the money for the meal). (for)

Как показала практика, подобные тестовые задания успешно выполняются студентами, усвоившими учебный материал.

Онлайн-тестирование является значительным шагом на пути развития методики контроля усвоения обучающимися учебного материала. Применение тестов в режиме реального времени на сегодняшний день зани- мает одно из ведущих мест среди технологий электронного обучения студентов, делая процесс познания не только эффективным и соответствующим требованиям стремительно меняющейся внешней среды, но и интересным. Именно дистанционные технологии оказались единственно возможными к использованию в условиях стремительного перехода высшего образования в дистанционный режим [3]. Введение тестирования позволяет осуществить плавный переход от субъективных и во многом интуитивных оценок к объективным обоснованным методам оценки результатов обучения. Однако, как и любое другое педагогическое нововведение, этот шаг должен осуществляться на строго научной базе, опираясь на результаты педагогических экспериментов и научных исследований. Тестирование не должно заменить традиционные методы педагогического контроля, а должно лишь в некоторой степени дополнить их.

\section{ЛИТЕРАТУРА}

1. Коровкина Д.В. Английский язык в профессии. Общественное питание. Практикум = English in the profession. Food catering. Course pack: yчебное пособие. - Минск: РИПО, 2017. - 76 с.

2. Мишина Т.Н. Использование онлайн-тестирования в образовательной системе СПО для мониторинга качества подготовки специалистов // https://s-ba.ru/ Высшая школа делового администрирования.

3. Орусова О.В. Как коронавирус изменил систему высшего образования: анализ перехода вузов на дистанционное обучение // Научное обозрение. Серия 1. Экономика и право. - 2020. - № 3. - С. 184-196.

4. Перова Ю.П. Технологии тестирования в дистанционном обучении // Управление, вычислительная техника и информатика. Доклады ТУСУРа. - 2015. №1 (35). - С. 138-141.

5. Саидмуратова У.Р. Тестирование как метод контроля и мониторинга знаний при обучении иностранным языкам в дистанционном образовании // Молодой ученый. - 2019. - № 19 (257). - С. 368-370.

6. Штыхно Д.А., Константинова Л.В., Гагиев Н.Н. Переход вузов в дистанционный режим в период пандемии: проблемы и возможные риски // Открытое образование. -2020 . - № 5. - Т. 24. - С. 72-81.

○ Климова Наталья Юрьевна (nazar11081@mail.ru), Коваленко Екатерина Святославовна (katusha.2013-kovalenko@yandex.ru), Горошко Ольга Николаевна (goroshko_olenka@mail.ru), Шевченко Елена Михайловна (lena.shevchenko.1976@list.ru).

Журнал «Современная наука: актуальные проблемы теории и практики» 